\title{
Research Article \\ Convergece Theorems for Finite Families of Asymptotically Quasi-Nonexpansive Mappings
}

\author{
C. E. Chidume and Bashir Ali
}

Received 20 October 2006; Revised 30 January 2007; Accepted 31 January 2007

Recommended by Donal O’Regan

Let $E$ be a real Banach space, $K$ a closed convex nonempty subset of $E$, and $T_{1}, T_{2}, \ldots, T_{m}$ : $K \rightarrow K$ asymptotically quasi-nonexpansive mappings with sequences (resp.) $\left\{k_{i n}\right\}_{n=1}^{\infty}$ satisfying $k_{i n} \rightarrow 1$ as $n \rightarrow \infty$, and $\sum_{n=1}^{\infty}\left(k_{i n}-1\right)<\infty, i=1,2, \ldots, m$. Let $\left\{\alpha_{n}\right\}_{n=1}^{\infty}$ be a sequence in $[\epsilon, 1-\epsilon], \epsilon \in(0,1)$. Define a sequence $\left\{x_{n}\right\}$ by $x_{1} \in K, x_{n+1}=\left(1-\alpha_{n}\right) x_{n}+$ $\alpha_{n} T_{1}^{n} y_{n+m-2}, y_{n+m-2}=\left(1-\alpha_{n}\right) x_{n}+\alpha_{n} T_{2}^{n} y_{n+m-3}, \ldots, y_{n}=\left(1-\alpha_{n}\right) x_{n}+\alpha_{n} T_{m}^{n} x_{n}, n \geq 1$, $m \geq 2$. Let $\bigcap_{i=1}^{m} F\left(T_{i}\right) \neq \varnothing$. Necessary and sufficient conditions for a strong convergence of the sequence $\left\{x_{n}\right\}$ to a common fixed point of the family $\left\{T_{i}\right\}_{i=1}^{m}$ are proved. Under some appropriate conditions, strong and weak convergence theorems are also proved.

Copyright (c) 2007 C. E. Chidume and B. Ali. This is an open access article distributed under the Creative Commons Attribution License, which permits unrestricted use, distribution, and reproduction in any medium, provided the original work is properly cited.

\section{Introduction}

Let $K$ be a nonempty subset of a real normed space $E$. A self-mapping $T: K \rightarrow K$ is called nonexpansive if $\|T x-T y\| \leq\|x-y\|$ for every $x, y \in K$, and quasi-nonexpansive if $F(T):=\{x \in K: T x=x\} \neq \varnothing$ and $\|T x-p\| \leq\|x-p\|$ for every $x \in K$ and $p \in F(T)$. The mapping $T$ is called asymptotically nonexpansive if there exists a sequence $\left\{k_{n}\right\} \subset$ $[1, \infty)$ with $k_{n} \rightarrow 1$ as $n \rightarrow \infty$ such that for every $n \in \mathbb{N}$,

$$
\left\|T^{n} x-T^{n} y\right\| \leq k_{n}\|x-y\| \quad \text { for every } x, y \in K
$$

If $F(T) \neq \varnothing$ and there exists a sequence $\left\{k_{n}\right\} \subset[1, \infty)$ with $k_{n} \rightarrow 1$ as $n \rightarrow \infty$ such that for 
$n \in \mathbb{N}$,

$$
\left\|T^{n} x-p\right\| \leq k_{n}\|x-p\| \quad \text { for every } x \in K,
$$

and $p \in F(T)$, then $T$ is called asymptotically quasi-nonexpansive mapping.

Iterative methods for approximating fixed points of nonexpansive mappings and their generalisations have been studied by numerous authors (see, e.g., [1-9] and the references contained therein).

Petryshyn and Williamson [4] proved necessary and sufficient conditions for the Picard and Mann [10] iterative sequences to strongly converge to a fixed point of a quasinonexpansive map $T$ in a real Banach space.

Ghosh and Debnath [3] extended the results in [4] and proved necessary and sufficient conditions for strong convergence of Ishikawa-type [11] iteration process to a fixed point of a quasi-nonexpansive mapping $T$ in a real Banach space. Furthermore, they proved strong convergence theorem of the Ishikawa-type iteration process for quasinonexpansive mappings in a uniformly convex Banach space.

Qihou [5] extended the results of Ghosh and Debnath to asymptotically quasi-nonexpansive mappings. In some other papers, Qihou [6,7] studied the convergence of Ishikawa-type iteration process with errors for asymtotically quasi-nonexpansive mappings.

Recently, Sun [12] studied the convergence of an implicit iteration process (see [12] for definition) to a common fixed point of finite family of asymptotically quasi-nonexpansive mappings. He proved the following theorems.

Theorem 1.1 (see [12]). Let $K$ be a nonempty closed convex subset of a Banach space $E$. Let $\left\{T_{i}, i \in I\right\}$ be $m$ asymptotically quasi-nonexpansive self-mappings of $K$ with sequences $\left\{1+u_{i n}\right\}_{n}, i=1,2, \ldots, m$, respectively. Suppose that $F:=\bigcap_{i=1}^{m} F\left(T_{i}\right) \neq \varnothing$ and that $x_{0} \in K$, $\left\{\alpha_{n}\right\} \subset(s, 1-s)$ for some $s \in(0,1), \sum_{n=1}^{\infty} u_{i n}<\infty$ for all $i \in I$. Then the implicit iterative sequence $\left\{x_{n}\right\}$ generated by

$$
x_{n}=\alpha_{n} x_{n-1}+\left(1-\alpha_{n}\right) T_{i}^{k} x_{n}, \quad n \geq 1, \quad n=(k-1) m+i, \quad i=1,2, \ldots, m,
$$

converges to a common fixed point in $F$ if and only if $\liminf _{n \rightarrow \infty} d\left(x_{n}, F\right)=0$, where $d\left(x_{n}, F\right)=\inf _{x^{*} \in F}\left\|x_{n}-x^{*}\right\|$.

Theorem 1.2 (see [12]). Let $K$ be a nonempty closed convex and bounded subset of a real uniformly convex Banach space E. Let $\left\{T_{i}, i \in I\right\}$ be $m$ uniformly L-Lipschitzian asymptotically quasi-nonexpansive self-mappings of $K$ with sequences $\left\{1+u_{i n}\right\}_{n}, i=1,2, \ldots, m$, respectively. Suppose that $F:=\bigcap_{i=1}^{m} F\left(T_{i}\right) \neq \varnothing$ and that $x_{0} \in K,\left\{\alpha_{n}\right\} \subset(s, 1-s)$ for some $s \in(0,1), \sum_{n=1}^{\infty} u_{\text {in }}<\infty$ for all $i \in I$. If there exists one member $T \in\left\{T_{i}, i \in I\right\}$ which is semicompact, then the implicit iterative sequence $\left\{x_{n}\right\}$ generated by (1.3) converges strongly to a common fixed point of the mappings $\left\{T_{i}, i \in I\right\}$.

Very recently, Shahzad and Udomene [8] proved necessary and sufficient conditions for the strong convergence of the Ishikawa-like iteration process to a common fixed point of two uniformly continuous asymptotically quasi-nonexpansive mappings.

Their main results are the following theorems. 
Theorem 1.3 (see [8]). Let $E$ be a real Banach space and let $K$ be a nonempty closed convex subset of $E$. Let $S, T: K \rightarrow K$ be two asymptotically quasi-nonexpansive mappings ( $S$ and $T$ need not be continuous) with sequences $\left\{u_{n}\right\},\left\{v_{n}\right\} \subset[0, \infty)$ such that $\sum u_{n}<\infty$ and $\sum v_{n}<$ $\infty$, and $F:=F(S) \cap F(T)=\{x \in K: S x=T x=x\} \neq \varnothing$. Let $\left\{\alpha_{n}\right\}$ and $\left\{\beta_{n}\right\}$ be sequences in $[0,1]$. From arbitrary $x_{1} \in K$ define a sequence $\left\{x_{n}\right\}$ by

$$
x_{n+1}=\left(1-\alpha_{n}\right) x_{n}+\alpha_{n} S^{n}\left[\left(1-\beta_{n}\right) x_{n}+\beta_{n} T^{n} x_{n}\right] .
$$

Then, $\left\{x_{n}\right\}$ converges strongly to some common fixed point of $S$ and $T$ if and only if $\liminf _{n \rightarrow \infty} d\left(x_{n}, F\right)=0$.

Theorem 1.4 (see [8]). Let E be a real uniformly convex Banach space and let $K$ be a nonempty closed convex subset of $E$. Let $S, T: K \rightarrow K$ be two uniformly continuous asymptotically quasi-nonexpansive mappings with sequences $\left\{u_{n}\right\},\left\{v_{n}\right\} \subset[0, \infty)$ such that $\sum u_{n}<\infty$, $\sum v_{n}<\infty$, and $F:=F(S) \cap F(T)=\{x \in K: S x=T x=x\} \neq \varnothing$. Let $\left\{\alpha_{n}\right\}$ and $\left\{\beta_{n}\right\}$ be sequences in $[\epsilon, 1-\epsilon]$ for some $\epsilon \in(0,1)$. From arbitrary $x_{1} \in K$ define a sequence $\left\{x_{n}\right\}$ by (1.4). Assume, in addition, that either $T$ or $S$ is compact. Then, $\left\{x_{n}\right\}$ converges strongly to some common fixed point of $S$ and $T$.

More recently, the authors [2] introduced a scheme defined by

$$
\begin{gathered}
x_{1} \in K, \\
x_{n+1}=P\left[\left(1-\alpha_{1 n}\right) x_{n}+\alpha_{1 n} T_{1}\left(P T_{1}\right)^{n-1} y_{n+m-2}\right], \\
y_{n+m-2}=P\left[\left(1-\alpha_{2 n}\right) x_{n}+\alpha_{2 n} T_{2}\left(P T_{2}\right)^{n-1} y_{n+m-3}\right], \\
\vdots \\
y_{n}=P\left[\left(1-\alpha_{m n}\right) x_{n}+\alpha_{m n} T_{m}\left(P T_{m}\right)^{n-1} x_{n}\right], \quad n \geq 1,
\end{gathered}
$$

and studied the convergence of this sheme to a common fixed point of finite families of nonself asymptotically nonexpansive mappings.

Let $\left\{\alpha_{n}\right\}$ be a real sequence in $[\epsilon, 1-\epsilon], \epsilon \in(0,1)$. Let $T_{1}, T_{2}, \ldots, T_{m}: K \rightarrow K$ be a family of mappings. Define a sequence $\left\{x_{n}\right\}$ by

$$
\begin{gathered}
x_{1} \in K, \\
x_{n+1}=\left(1-\alpha_{n}\right) x_{n}+\alpha_{n} T_{1}^{n} y_{n+m-2}, \\
y_{n+m-2}=\left(1-\alpha_{n}\right) x_{n}+\alpha_{n} T_{2}^{n} y_{n+m-3}, \\
\vdots \\
y_{n}=\left(1-\alpha_{n}\right) x_{n}+\alpha_{n} T_{m}^{n} x_{n}, \quad n \geq 1 .
\end{gathered}
$$

It is our purpose in this paper to prove necessary and sufficient conditions for the strong convergence of the scheme defined by (1.6) to a common fixed point of finite family $T_{1}, T_{2}, \ldots, T_{m}$ of asymptotically quasi-nonexpansive mappings. We also prove strong and weak convergence theorems for the family in a uniformly convex Banach spaces. Our results generalize and improve some recent important results (see Remark 3.9). 
4 Journal of Inequalities and Applications

\section{Preliminaries}

Let $E$ be a real normed linear space. The modulus of convexity of $E$ is the function $\delta_{E}$ : $(0,2] \rightarrow[0,1]$ defined by

$$
\delta_{E}(\epsilon)=\inf \left\{1-\left\|\frac{x+y}{2}\right\|:\|x\|=\|y\|=1, \epsilon=\|x-y\|\right\}
$$

$E$ is called uniformly convex if and only if $\delta_{E}(\epsilon)>0 \forall \epsilon \in(0,2]$.

A mapping $T$ with domain $D(T)$ and range $R(T)$ in $E$ is said to be demiclosed at $p$ if whenever $\left\{x_{n}\right\}$ is a sequence in $D(T)$ such that $x_{n} \rightarrow x^{*} \in D(T)$ and $T x_{n} \rightarrow p$ then $T x^{*}=p$.

A mapping $T: K \rightarrow K$ is said to be semicompact if, for any bounded sequence $\left\{x_{n}\right\}$ in $K$ such that $\left\|x_{n}-T x_{n}\right\| \rightarrow 0$ as $n \rightarrow \infty$, there exists a subsequence say $\left\{x_{n_{j}}\right\}$ of $\left\{x_{n}\right\}$ such that $\left\{x_{n_{j}}\right\}$ converges strongly to some $x^{*}$ in $K$.

A Banach space $E$ is said to satisfy Opial's condition if for any sequence $\left\{x_{n}\right\}$ in $E$, $x_{n} \rightarrow x$ implies that

$$
\liminf _{n \rightarrow \infty}\left\|x_{n}-x\right\|<\liminf _{n \rightarrow \infty}\left\|x_{n}-y\right\| \quad \forall y \in E, y \neq x
$$

We will say that a mapping $T$ satisfies condition $(P)$ if it satisfies the weak version of demiclosedness at origin as defined in [4] (i.e., if $\left\{x_{n_{j}}\right\}$ is any subsequence of a sequence $\left\{x_{n}\right\}$ with $x_{n_{j}} \rightarrow x^{*}$ and $(I-T) x_{n_{j}} \rightarrow 0$ as $j \rightarrow \infty$, then $\left.x^{*}-T x^{*}=0\right)$.

In what follows we will use the following results.

LemmA 2.1 (see [9]). Let $\left\{\lambda_{n}\right\}$ and $\left\{\sigma_{n}\right\}$ be sequences of nonnegative real numbers such that $\lambda_{n+1} \leq \lambda_{n}+\sigma_{n}$ for all $n \geq 1$, and $\sum_{n=1}^{\infty} \sigma_{n}<\infty$, then $\lim _{n \rightarrow \infty} \lambda_{n}$ exists. Moreover, if there exists a subsequence $\left\{\lambda_{n_{j}}\right\}$ of $\left\{\lambda_{n}\right\}$ such that $\lambda_{n_{j}} \rightarrow 0$ as $j \rightarrow \infty$, then $\lambda_{n} \rightarrow 0$ as $n \rightarrow \infty$.

Lemma 2.2 (see [13]). Let $p>1$ and $r>1$ be two fixed numbers and $E$ a Banach space. Then $E$ is uniformly convex if and only if there exists a continuous, strictly increasing, and convex function $g:[0, \infty) \rightarrow[0, \infty)$ with $g(0)=0$ such that

$$
\|\lambda x+(1-\lambda) y\|^{p} \leq \lambda\|x\|^{p}+(1-\lambda)\|y\|^{p}-W_{p}(\lambda) g(\|x-y\|)
$$

for all $x, y \in B_{r}(0)=\{z \in E:\|z\| \leq r\}, \lambda \in[0,1]$ and $W_{p}(\lambda)=\lambda(1-\lambda)^{p}+\lambda^{p}(1-\lambda)$.

\section{Main results}

In this section, we state and prove the main results of this paper. In the sequel, we designate the set $\{1,2, \ldots, m\}$ by $I$ and we always assume $F:=\bigcap_{i=1}^{m} F\left(T_{i}\right) \neq \varnothing$.

Lemma 3.1. Let $E$ be a real normed linear space and let $K$ be a nonempty, closed convex subset of $E$. Let $T_{1}, T_{2}, \ldots, T_{m}: K \rightarrow K$ be asymptotically quasi-nonexpansive mappings with sequence $\left\{k_{i n}\right\}_{n=1}^{\infty}$ satisfying $k_{i n} \rightarrow 1$ as $n \rightarrow \infty$ and $\sum_{n=1}^{\infty}\left(k_{i n}-1\right)<\infty, i \in I$. Let $\left\{\alpha_{n}\right\}_{n=1}^{\infty}$ be 
a sequences in $[\epsilon, 1-\epsilon], \epsilon \in(0,1)$. Let $\left\{x_{n}\right\}$ be a sequence defined iteratively by

$$
\begin{gathered}
x_{1} \in K, \\
x_{n+1}=\left(1-\alpha_{n}\right) x_{n}+\alpha_{n} T_{1}^{n} y_{n+m-2}, \\
y_{n+m-2}=\left(1-\alpha_{n}\right) x_{n}+\alpha_{n} T_{2}^{n} y_{n+m-3}, \\
\vdots \\
y_{n}=\left(1-\alpha_{n}\right) x_{n}+\alpha_{n} T_{m}^{n} x_{n}, \quad n \geq 1, m \geq 2 .
\end{gathered}
$$

Let $x^{*} \in F$. Then, $\left\{x_{n}\right\}$ is bounded and the limits $\lim _{n \rightarrow \infty}\left\|x_{n}-x^{*}\right\|$ and $\lim _{n \rightarrow \infty} d\left(x_{n}, F\right)$ exist, where $d\left(x_{n}, F\right)=\inf _{x^{*} \in F}\left\|x_{n}-x^{*}\right\|$.

Proof. Set $k_{i n}=1+u_{i n}$ so that $\sum_{n=1}^{\infty} u_{i n}<\infty$ for each $i \in I$. Let $w_{n}:=\sum_{i=1}^{m} u_{i n}$. Let $x^{*} \in F$. Then we have, for some positive integer $h, 2 \leq h<m$,

$$
\begin{aligned}
\left\|x_{n+1}-x^{*}\right\|= & \left\|\left(1-\alpha_{n}\right) x_{n}+\alpha_{n} T_{1}^{n} y_{n+m-2}-x^{*}\right\| \\
\leq & \left(1-\alpha_{n}\right)\left\|x_{n}-x^{*}\right\|+\alpha_{n}\left(1+u_{1 n}\right)\left\|y_{n+m-2}-x^{*}\right\| \\
\leq & \left(1-\alpha_{n}\right)\left\|x_{n}-x^{*}\right\| \\
& +\alpha_{n}\left(1+u_{1 n}\right)\left[\left(1-\alpha_{n}\right)\left\|x_{n}-x^{*}\right\|+\alpha_{n}\left(1+u_{2 n}\right)\left\|y_{n+m-3}-x^{*}\right\|\right] \\
\leq & \left(1-\alpha_{n}\right)\left\|x_{n}-x^{*}\right\|+\alpha_{n}\left(1-\alpha_{n}\right)\left(1+u_{1 n}\right)\left\|x_{n}-x^{*}\right\| \\
& +\cdots+\left(\alpha_{n}\right)^{h-1}\left(1-\alpha_{n}\right)\left(1+u_{1 n}\right)\left(1+u_{2 n}\right) \cdots\left(1+u_{h-1 n}\right)\left\|x_{n}-x^{*}\right\| \\
& +\cdots+\left(\alpha_{n}\right)^{m}\left(1+u_{1 n}\right)\left(1+u_{2 n}\right) \cdots\left(1+u_{m n}\right)\left\|x_{n}-x^{*}\right\| \\
\leq & \left\|x_{n}-x^{*}\right\|\left[1+u_{1 n}+u_{2 n}\left(1+u_{1 n}\right)+u_{3 n}\left(1+u_{1 n}\right)\left(1+u_{2 n}\right)+\cdots\right. \\
& \left.+u_{m n}\left(1+u_{1 n}\right)\left(1+u_{2 n}\right) \cdots\left(1+u_{m-1 n}\right)\right] \\
\leq & \left\|x_{n}-x^{*}\right\|\left[1+\left(\begin{array}{c}
m \\
1
\end{array}\right) w_{n}+\left(\begin{array}{c}
m \\
2
\end{array}\right) w_{n}^{2}+\cdots+\left(\begin{array}{c}
m \\
m
\end{array}\right) w_{n}^{m}\right] \\
\leq & \left\|x_{n}-x^{*}\right\|\left(1+\delta_{m} w_{n}\right) \leq\left\|x_{n}-x^{*}\right\| e^{\delta_{m} w_{n}} \\
\leq & \left\|x_{1}-x^{*}\right\| e^{\delta_{m} \sum_{n=1}^{\infty} w_{n}<\infty,}
\end{aligned}
$$

where $\delta_{m}$ is a positive real number defined by $\delta_{m}:=\left[\left(\begin{array}{c}m \\ 1\end{array}\right)+\left(\begin{array}{c}m \\ 2\end{array}\right)+\cdots+\left(\begin{array}{c}m \\ m\end{array}\right)\right]$.

This implies that $\left\{x_{n}\right\}$ is bounded and so there exists a positive integer $M$ such that

$$
\left\|x_{n+1}-x^{*}\right\| \leq\left\|x_{n}-x^{*}\right\|+\delta_{m} M w_{n} .
$$


6 Journal of Inequalities and Applications

Since (3.3) is true for each $x^{*}$ in $F$, we have

$$
d\left(x_{n+1}, F\right) \leq d\left(x_{n}, F\right)+\delta_{m} M w_{n} .
$$

By Lemma 2.1, $\lim _{n \rightarrow \infty}\left\|x_{n}-x^{*}\right\|$ and $\lim _{n \rightarrow \infty} d\left(x_{n}, F\right)$ exist. This completes the proof of Lemma 3.1.

Theorem 3.2. Let $K$ be a nonempty closed convex subset of a Banach space E. Let $T_{1}, T_{2}, \ldots$, $T_{m}: K \rightarrow K$ be asymptotically quasi-nonexpansive mappings with sequences $\left\{k_{i n}\right\}_{n=1}^{\infty}$ and $\left\{\alpha_{n}\right\}_{n=1}^{\infty}$ as in Lemma 3.1. Let $\left\{x_{n}\right\}$ be defined by (3.1). Then, $\left\{x_{n}\right\}$ converges to a common fixed point of the family $T_{1}, T_{2}, \ldots, T_{m}$ if and only if $\liminf _{n \rightarrow \infty} d\left(x_{n}, F\right)=0$.

Proof. The necessity is trivial. We prove the sufficiency. Let $\liminf _{n \rightarrow \infty} d\left(x_{n}, F\right)=0$. Since $\lim _{n \rightarrow \infty} d\left(x_{n}, F\right)$ exists by Lemma 3.1, we have that $\lim _{n \rightarrow \infty} d\left(x_{n}, F\right)=0$. Thus, given $\epsilon>0$ there exist a positive integer $N_{0}$ and $b^{*} \in F$ such that for all $n \geq N_{0}\left\|x_{n}-b^{*}\right\|<\epsilon / 2$. Then, for any $k \in \mathbb{N}$, we have for $n \geq N_{0}$,

$$
\left\|x_{n+k}-x_{n}\right\| \leq\left\|x_{n+k}-b^{*}\right\|+\left\|b^{*}-x_{n}\right\|<\frac{\epsilon}{2}+\frac{\epsilon}{2}=\epsilon,
$$

and so $\left\{x_{n}\right\}$ is Cauchy. Let $\lim _{n \rightarrow \infty} x_{n}=b$. We need to show that $b \in F$. Let $T_{i} \in\left\{T_{1}, T_{2}, \ldots\right.$, $\left.T_{m}\right\}$. Since $\lim _{n \rightarrow \infty} d\left(x_{n}, F\right)=0$, there exists $N \in \mathbb{N}$ sufficiently large and $b^{*} \in F$ such that $n \geq N$ implies $\left\|b-x_{n}\right\|<\epsilon / 6\left(1+w_{1}\right),\left\|b^{*}-x_{n}\right\|<\epsilon / 6\left(1+w_{1}\right)$. Then, $\left\|b^{*}-b\right\|<\epsilon / 3(1+$ $\left.w_{1}\right)$. Thus, we have the following estimates, for $n \geq N$ and arbitrary $T_{i}, i=1,2, \ldots, m$,

$$
\begin{aligned}
\left\|b-T_{i} b\right\| & \leq\left\|b-x_{n}\right\|+\left\|x_{n}-b^{*}\right\|+\left\|b^{*}-T_{i} b\right\| \\
& \leq\left\|b-x_{n}\right\|+\left\|x_{n}-b^{*}\right\|+\left(1+w_{1}\right)\left\|b^{*}-b\right\| \\
& <\frac{\epsilon}{3\left(1+w_{1}\right)}+\frac{\epsilon}{3\left(1+w_{1}\right)}+\frac{\epsilon}{3} \leq \epsilon .
\end{aligned}
$$

This implies that $b \in \operatorname{Fix}\left(T_{i}\right)$ for all $i=1,2, \ldots, m$ and thus $b \in F$. This completes the proof.

Corollary 3.3. Let $K$ be a nonempty closed convex subset of a Banach space E. Let $T_{1}$, $T_{2}, \ldots, T_{m}: K \rightarrow K$ be quasi-nonexpansive mappings. Let the sequence $\left\{\alpha_{n}\right\}_{n=1}^{\infty}$ be as in Lemma 3.1. Let $\left\{x_{n}\right\}$ be defined by

$$
\begin{gathered}
x_{1} \in K \\
x_{n+1}=\left(1-\alpha_{n}\right) x_{n}+\alpha_{n} T_{1} y_{n+m-2}, \\
y_{n+m-2}=\left(1-\alpha_{n}\right) x_{n}+\alpha_{n} T_{2} y_{n+m-3}, \\
\vdots \\
y_{n}=\left(1-\alpha_{n}\right) x_{n}+\alpha_{n} T_{m} x_{n}, \quad n \geq 1 .
\end{gathered}
$$

Then, $\left\{x_{n}\right\}$ converges to a common fixed point of the family $T_{1}, T_{2}, \ldots, T_{m}$ if and only if $\liminf _{n \rightarrow \infty} d\left(x_{n}, F\right)=0$. 
For our next theorems, we start by proving the following lemma which will be needed in the sequel.

Lemma 3.4. Let $E$ be a real uniformly convex Banach space and let $K$ be a closed convex nonempty subset of $E$. Let $T_{1}, T_{2}, \ldots, T_{m}: K \rightarrow K$ be uniformly continuous asymptotically quasi-nonexpansive mappings with sequences $\left\{k_{i n}\right\}_{n=1}^{\infty}$ satisfying $k_{i n} \rightarrow 1$ as $n \rightarrow \infty$ and $\sum_{n=1}^{\infty}\left(k_{\text {in }}-1\right)<\infty, i=1,2, \ldots, m$. Let $\left\{\alpha_{n}\right\}_{n=1}^{\infty}$ be a sequence in $[\epsilon, 1-\epsilon], \epsilon \in(0,1)$. Let $\left\{x_{n}\right\}$ be a sequence defined iteratively by (3.1). Then,

$$
\lim _{n \rightarrow \infty}\left\|x_{n}-T_{1} x_{n}\right\|=\lim _{n \rightarrow \infty}\left\|x_{n}-T_{2} x_{n}\right\|=\cdots=\lim _{n \rightarrow \infty}\left\|x_{n}-T_{m} x_{n}\right\|=0 .
$$

Proof. Since $\left\{x_{n}\right\}$ is bounded, for some $x^{*} \in F$, there exists a positive real number $\gamma$ such that $\left\|x_{n}-x^{*}\right\|^{2} \leq \gamma$ for all $n \geq 1$. By using Lemma 2.2 and the recursion formula (3.1), we have

$$
\begin{aligned}
\left\|y_{n}-x^{*}\right\|^{2} & =\left\|\left(1-\alpha_{n}\right)\left(x_{n}-x^{*}\right)+\alpha_{n}\left(T_{m}^{n} x_{n}-x^{*}\right)\right\|^{2} \\
& \leq\left(1-\alpha_{n}\right)\left\|x_{n}-x^{*}\right\|^{2}+\alpha_{n}\left(1+u_{m n}\right)^{2}\left\|x_{n}-x^{*}\right\|^{2}-\alpha_{n}\left(1-\alpha_{n}\right) g\left(\left\|x_{n}-T_{m}^{n} x_{n}\right\|\right) \\
& \leq\left\|x_{n}-x^{*}\right\|^{2}+\alpha_{n}\left(2 u_{m n}+u_{m n}^{2}\right)\left\|x_{n}-x^{*}\right\|^{2}-\epsilon^{2} g\left(\left\|x_{n}-T_{m}^{n} x_{n}\right\|\right) \\
& \leq\left\|x_{n}-x^{*}\right\|^{2}+3 w_{n} \gamma-\epsilon^{2} g\left(\left\|x_{n}-T_{m}^{n} x_{n}\right\|\right) .
\end{aligned}
$$

Also

$$
\begin{aligned}
\left\|y_{n+1}-x^{*}\right\|^{2}= & \left\|\left(1-\alpha_{n}\right)\left(x_{n}-x^{*}\right)+\alpha_{n}\left(T_{m-1}^{n} y_{n}-x^{*}\right)\right\|^{2} \\
\leq & \left(1-\alpha_{n}\right)\left\|x_{n}-x^{*}\right\|^{2}+\alpha_{n}\left(1+u_{m-1 n}\right)^{2}\left\|y_{n}-x^{*}\right\|^{2} \\
& -\alpha_{n}\left(1-\alpha_{n}\right) g\left(\left\|x_{n}-T_{m-1}^{n} y_{n}\right\|\right) \\
\leq & \left(1-\alpha_{n}\right)\left\|x_{n}-x^{*}\right\|^{2}+\alpha_{n}\left(1+2 u_{m-1 n}+u_{m-1 n}^{2}\right)\left\|y_{n}-x^{*}\right\|^{2} \\
& -\epsilon^{2} g\left(\left\|x_{n}-T_{m-1}^{n} y_{n}\right\|\right) \leq\left(1-\alpha_{n}\right)\left\|x_{n}-x^{*}\right\|^{2} \\
& +\alpha_{n}\left(1+3 u_{m-1 n}\right)\left[\left\|x_{n}-x^{*}\right\|^{2}+3 w_{n} \gamma-\epsilon^{2} g\left(\left\|x_{n}-T_{m}^{n} x_{n}\right\|\right)\right] \\
& -\epsilon^{2} g\left(\left\|x_{n}-T_{m-1}^{n} y_{n}\right\|\right) \\
\leq & \left\|x_{n}-x^{*}\right\|^{2}+3 w_{n} \gamma-\epsilon^{3} g\left(\left\|x_{n}-T_{m}^{n} x_{n}\right\|\right)+3 w_{n} \gamma+\left(3 w_{n}\right)^{2} \gamma \\
& -3 w_{n} \epsilon^{3} g\left(\left\|x_{n}-T_{m}^{n} x_{n}\right\|\right)-\epsilon^{2} g\left(\left\|x_{n}-T_{m-1}^{n} y_{n}\right\|\right) \\
\leq & \left\|x_{n}-x^{*}\right\|^{2}+3^{3} w_{n} \gamma-\epsilon^{3}\left[g\left(\left\|x_{n}-T_{m}^{n} x_{n}\right\|\right)+g\left(\left\|x_{n}-T_{m-1}^{n} y_{n}\right\|\right)\right] .
\end{aligned}
$$

Continuing in this fashion we get, using $x_{n+1}=\left(1-\alpha_{n}\right) x_{n}+\alpha_{n} T_{1} y_{n+m-2}$, that

$$
\begin{aligned}
\left\|x_{n+1}-x^{*}\right\|^{2} \leq & \left\|x_{n}-x^{*}\right\|^{2}+3^{2 m-1} w_{n} \gamma \\
& -\epsilon^{m+1}\left(g\left(\left\|x_{n}-T_{m}^{n} x_{n}\right\|\right)+\sum_{k=1}^{m-1} g\left(\left\|x_{n}-T_{m-k}^{n} y_{n+k-1}\right\|\right)\right),
\end{aligned}
$$


8 Journal of Inequalities and Applications

so that

$$
\begin{gathered}
\epsilon^{m+1}\left(g\left(\left\|x_{n}-T_{m}^{n} x_{n}\right\|\right)+\sum_{k=1}^{m-1} g\left(\left\|x_{n}-T_{m-k}^{n} y_{n+k-1}\right\|\right)\right) \\
\leq\left\|x_{n}-x^{*}\right\|^{2}-\left\|x_{n+1}-x^{*}\right\|^{2}+3^{2 m-1} w_{n} \gamma .
\end{gathered}
$$

This implies that

$$
\epsilon^{m+1} \sum_{n=1}^{\infty}\left(g\left(\left\|x_{n}-T_{m}^{n} x_{n}\right\|\right)+\sum_{k=1}^{m-1} g\left(\left\|x_{n}-T_{m-k}^{n} y_{n+k-1}\right\|\right)\right)<\infty,
$$

and by the property of $g$, we have

$$
\begin{aligned}
\lim _{n \rightarrow \infty}\left\|x_{n}-T_{m}^{n} x_{n}\right\| & =\lim _{n \rightarrow \infty}\left\|x_{n}-T_{m-1}^{n} y_{n}\right\| \\
\vdots & \\
& =\lim _{n \rightarrow \infty}\left\|x_{n}-T_{h}^{n} y_{n+m-h-1}\right\| \\
\vdots & \\
& =\lim _{n \rightarrow \infty}\left\|x_{n}-T_{1}^{n} y_{n+m-2}\right\|=0
\end{aligned}
$$

for $2 \leq h<m$.

Now,

$$
\left\|x_{n}-T_{h} x_{n}\right\| \leq\left\|x_{n}-T_{h}^{n} y_{n+m-h-1}\right\|+\left\|T_{h}^{n} y_{n+m-h-1}-T_{h} x_{n}\right\|
$$

but $\left(T_{h}^{n-1} y_{n+m-h-1}-x_{n}\right) \rightarrow 0$ as $n \rightarrow \infty$, and since $T_{h}$ is uniformly continuous we have that $\left(T_{h}^{n} y_{n+m-1}-T_{h} x_{n}\right) \rightarrow 0$ as $n \rightarrow \infty$. So, from inequality (3.15), we get $\lim _{n \rightarrow \infty} \| x_{n}-$ $T_{h} x_{n} \|=0$. Also for $h=m$, from (3.14) we have

$$
\lim _{n \rightarrow \infty}\left\|x_{n}-T_{m}^{n} x_{n}\right\|=0
$$

Moreover,

$$
\left\|x_{n}-T_{m} x_{n}\right\| \leq\left\|x_{n}-T_{m}^{n} x_{n}\right\|+\left\|T_{m}^{n} x_{n}-T_{m} x_{n}\right\|
$$

Similarly, since $\left\|T_{m}^{n-1} x_{n}-x_{n}\right\| \rightarrow 0$ as $n \rightarrow \infty$ and $T_{m}$ is uniformly continuous, we have $\left(T_{m}^{n} x_{n}-T_{m} x_{n}\right) \rightarrow 0$ as $n \rightarrow \infty$ hence from (3.17) we get $\lim _{n \rightarrow \infty}\left\|x_{n}-T_{m} x_{n}\right\|=0$, and this completes the proof.

Theorem 3.5. Let $E$ be a real uniformly convex Banach space and let $K$ be a closed convex nonempty subset of $E$. Let $T_{1}, T_{2}, \ldots, T_{m}: K \rightarrow K$ be uniformly continuous asymptotically quasi-nonexpansive mappings with sequences $\left\{k_{i n}\right\}_{n=1}^{\infty}$ and $\left\{\alpha_{n}\right\}_{n=1}^{\infty}$ as in Lemma 3.4. If at 
least one member of $\left\{T_{i}\right\}_{i=1}^{m}$ is semicompact, then $\left\{x_{n}\right\}$ converges strongly to a common fixed point of the family $\left\{T_{i}\right\}_{i=1}^{m}$.

Proof. Assume $T_{d} \in\left\{T_{i}\right\}_{i=1}^{m}$ is semicompact. Since $\left\{x_{n}\right\}$ is bounded and by Lemma 3.4 $\left\|x_{n}-T_{d} x_{n}\right\| \rightarrow 0$ as $n \rightarrow \infty$, there exists a subsequence say $\left\{x_{n_{j}}\right\}$ of $\left\{x_{n}\right\}$ converging strongly to say $x \in K$. By the uniform continuity of $T_{d}, x=T_{d} x$. Using $x_{n_{j}} \rightarrow x, \| x_{n_{j}}-$ $T_{i} x_{n_{j}} \| \rightarrow 0$ as $j \rightarrow \infty$, and the continuity of $T_{i}$ for each $i \in\{1,2, \ldots, m\}$, we have that $x \in \bigcap_{i=1}^{m} \operatorname{Fix}\left(T_{i}\right)$. By Lemma 3.1, $\lim \left\|x_{n}-x\right\|$ exists, hence, $\left\{x_{n}\right\}$ converges strongly to a common fixed point of the family $\left\{T_{i}\right\}_{i=1}^{m}$.

Corollary 3.6. Let $E$ be a real uniformly convex Banach space and let $K$ be a closed convex nonempty subset of $E$. Let $T_{1}, T_{2}, \ldots, T_{m}: K \rightarrow K$ be uniformly continuous quasinonexpansive mappings. Let $\left\{\alpha_{n}\right\}_{n=1}^{\infty}$ be a sequence as in Corollary 3.3. If one of $\left\{T_{i}\right\}_{i=1}^{m}$ is semicompact, then $\left\{x_{n}\right\}$ defined by (3.7) converges strongly to a common fixed point of the family $\left\{T_{i}\right\}_{i=1}^{m}$.

We now prove weak convergence theorems.

Theorem 3.7. Let $E$ be a real uniformly convex Banach space and let $K$ be a closed convex nonempty subset of $E$. Let $T_{1}, T_{2}, \ldots, T_{m}: K \rightarrow K$ be uniformly continuous asymptotically quasi-nonexpansive mappings with sequences $\left\{k_{i n}\right\}_{n=1}^{\infty}$ and $\left\{\alpha_{n}\right\}_{n=1}^{\infty}$ as in Lemma 3.4. If $E$ satisfies Opial's condition and each $T_{i}, i \in I$, satisfies condition $P$, then the sequence $\left\{x_{n}\right\}$ defined by (3.1) converges weakly to a common fixed point of $\left\{T_{i}\right\}_{i=1}^{m}$.

Proof. Since $\left\{x_{n}\right\}$ is bounded and $E$ is reflexive, there exists a subsequence say $\left\{x_{n_{k}}\right\}$ of $\left\{x_{n}\right\}$, converging weakly to some point say $p \in K$. By Lemma 3.4, $\left\|x_{n_{k}}-T_{i} x_{n_{k}}\right\| \rightarrow 0$ as $k \rightarrow \infty$. Condition $(P)$ of each $T_{i}$ guarantees that $p \in \omega\left(\left\{x_{n}\right\}\right) \cap \bigcap_{i=1}^{m} \operatorname{Fix}\left(T_{i}\right)$. If we have another subsequence of $\left\{x_{n}\right\}$ converging to another point say $x^{\prime} \in K$, by similar argument we can easily show that $x^{\prime} \in \omega\left(\left\{x_{n}\right\}\right) \cap \bigcap_{i=1}^{m} \operatorname{Fix}\left(T_{i}\right)$. Since $E$ satisfies Opial's condition, using standard argument we get that $x^{\prime}=p$, completing the proof.

The following corollary follows from Theorem 3.7.

Corollary 3.8. Let $K$ be a nonempty closed convex subset of a real uniformly convex $B a-$ nach space $E$. Let $T_{1}, T_{2}, \ldots, T_{m}: K \rightarrow K$ be uniformly continuous quasi-nonexpansive mappings. Let the sequence $\left\{\alpha_{n}\right\}_{n=1}^{\infty}$ be as in Corollary 3.3. If E satisfies Opial's condition and at least one of the $T_{i}$ 's $i \in I$ satisfies condition $P$, then the sequence $\left\{x_{n}\right\}$ defined by (3.7) converges weakly to a common fixed point of $\left\{T_{i}\right\}_{i=1}^{m}$.

Remark 3.9. Theorem 3.2 extends [8, Theorem 3.2]. In the same way, Theorem 3.5 extends [8, Theorem 3.4] to finite family of asymptotically quasi-nonexpansive mappings, and includes as a special case [8, Theorem 3.7]. In addition, the condition of compactness on the operators imposed in [8, Theorem 3.4] is weaken, replacing it by semicompactness in Theorem 3.5. It is clear that if $T$ is compact, then it is semicompact and satisfies condition $P$. The scheme studied in [12] is implicit and not iterative. Our scheme is iterative.

Remark 3.10. Addition of bounded error terms to any of the recurrence relations in our iteration methods leads to no further generalization. 


\section{Acknowledgments}

The authors thank the referee for the very useful comments which helped to improve this work. The research of the second author was supported by the Japanese Mori Fellowship of UNESCO at The Abdus Salam International Centre for Theoretical Physics, Trieste, Italy.

\section{References}

[1] C. E. Chidume, H. Zegeye, and N. Shahzad, "Convergence theorems for a common fixed point of a finite family of nonself nonexpansive mappings," Fixed Point Theory and Applications, vol. 2005, no. 2, pp. 233-241, 2005.

[2] C. E. Chidume and B. Ali, "Approximation of common fixed points for finite families of nonself asymptotically nonexpansive mappings in Banach spaces," Journal of Mathematical Analysis and Applications, vol. 326, no. 2, pp. 960-973, 2007.

[3] M. K. Ghosh and L. Debnath, "Convergence of Ishikawa iterates of quasi-nonexpansive mappings," Journal of Mathematical Analysis and Applications, vol. 207, no. 1, pp. 96-103, 1997.

[4] W. V. Petryshyn and T. E. Williamson Jr., "Strong and weak convergence of the sequence of successive approximations for quasi-nonexpansive mappings," Journal of Mathematical Analysis and Applications, vol. 43, no. 2, pp. 459-497, 1973.

[5] L. Qihou, "Iterative sequences for asymptotically quasi-nonexpansive mappings," Journal of Mathematical Analysis and Applications, vol. 259, no. 1, pp. 1-7, 2001.

[6] L. Qihou, "Iterative sequences for asymptotically quasi-nonexpansive mappings with error member," Journal of Mathematical Analysis and Applications, vol. 259, no. 1, pp. 18-24, 2001.

[7] L. Qihou, "Iteration sequences for asymptotically quasi-nonexpansive mapping with an error member of uniform convex Banach space," Journal of Mathematical Analysis and Applications, vol. 266, no. 2, pp. 468-471, 2002.

[8] N. Shahzad and A. Udomene, "Approximating common fixed points of two asymptotically quasi-nonexpansive mappings in Banach spaces," Fixed Point Theory and Applications, vol. 2006, Article ID 18909, 10 pages, 2006.

[9] K. K. Tan and H. K. Xu, "Approximating fixed points of nonexpansive mappings by the Ishikawa iteration process," Journal of Mathematical Analysis and Applications, vol. 178, no. 2, pp. 301308, 1993.

[10] W. R. Mann, "Mean value methods in iteration," Proceedings of the American Mathematical Society, vol. 4, no. 3, pp. 506-510, 1953.

[11] S. Ishikawa, "Fixed points by a new iteration method," Proceedings of the American Mathematical Society, vol. 44, no. 1, pp. 147-150, 1974.

[12] Z. H. Sun, "Strong convergence of an implicit iteration process for a finite family of asymptotically quasi-nonexpansive mappings," Journal of Mathematical Analysis and Applications, vol. 286, no. 1, pp. 351-358, 2003.

[13] Z.-B. Xu and G. F. Roach, "Characteristic inequalities of uniformly convex and uniformly smooth Banach spaces," Journal of Mathematical Analysis and Applications, vol. 157, no. 1, pp. 189-210, 1991.

C. E. Chidume: Mathematics Section, The Abdus Salam International Centre for Theoretical Physics, 34014 Trieste, Italy

Email address: chidume@ictp.trieste.it

Bashir Ali: Department of Mathematical Sciences, Bayero University, Kano, Nigeria

Email address: bashiralik@yahoo.com 